\title{
Communicating evolution with a Dynamic Evolutionary Map
}

\section{Sonia H. Stephens}

\begin{abstract}
Metaphors and visualizations are important for science communication, though they may have limitations. This paper describes the development and evaluation of a novel interactive visualization, the "Dynamic Evolutionary Map" (DEM), which communicates biological evolution using a non-standard metaphor. The DEM uses a map metaphor and interactivity to address conceptual limitations of traditional tree-based evolutionary representations. In a pilot evaluation biology novices used the DEM to answer questions about evolution. The results suggest that this visualization communicates some conceptual affordances differently than trees. Therefore, the described approach of building alternative visual metaphors for challenging concepts appears useful for science communication.
\end{abstract}

KEYWORDS: Images and representations of science and technology

\section{Context}

Visual models, analogies, and other diagrammatic representations are used extensively to support scientific thinking [1], educate students [2], and convey science informally to the public [3]. Diagrams aid in communicating technical information about structure, function, and physical properties, particularly for structures or phenomena that are diverse in scale or difficult to observe in person. They communicate these ideas through conceptual affordances, which are visual cues that suggest new mental associations to the reader [4]. Some representations use metaphor to suggest conceptual affordances. For example, Friedrich Kekule linked the chemical arrangement of atoms in benzene to the image of a snake biting its own tail [5]. Others are more analogical in nature, highlighting explicit similarities and differences between two domains, and facilitating predictive connections between the image and the object or system being represented [6, 7]. An analogical example is the Bohr model of atomic structure depicting electrons orbiting the nucleus of an atom similarly to the Solar System model of planets orbiting a star. In both of these models, one set of objects is constrained by some force to orbit another object, though both the objects and the forces are different.

Like Kekule's snake and the Bohr model, visualizations of evolution have included both metaphorical and analogical elements. Within the field of biology, branching diagrams called phylogenetic trees illustrate both the pattern of evolutionary history and the 
process that produces that pattern, shared descent with modification [8]. Phylogenetic trees provide a science-based framework for thinking about the pattern and process of evolution [9] and have analogical elements linked to formal hypotheses about relationships among organisms. However, more metaphoric tree-like imagery is also used to represent evolutionary pattern. Tree-like diagrams have been used to represent relationships among taxa (biological groups) for several centuries [10]. When Charles Darwin selected an image to represent his theory of evolution in On the Origin of Species, he used the visual metaphor of a "tree of life." This metaphor represents the broad scope and branching pattern of evolution over time by the image of a tree whose growth is shaped by shared descent [11]. Tree of life imagery is used today in a variety of communication settings, including museums and textbooks.

According to interaction theory, metaphors help people make associations between familiar concepts or objects and new ones, providing insight and suggesting that certain interpretations of novel information are more likely to be correct than others [12]. The metaphoric features of tree imagery help viewers link the features of a familiar object (a tree) to a less familiar concept (evolution). As with any other metaphor, however, the features of a tree do not map completely to the scientific understanding of the processes and patterns of evolution. When tree-based diagrams are used for communication, they may support viewers' existing misconceptions and reinforce an inaccurate understanding of evolution [13].

For example, the upward growth of a single-trunked tree may reinforce the notion that evolution is directed towards a goal [14], and has been shown to support the misconception that taxa located higher in the tree are superior to those lower down [15]. A tree's singular trunk also suggests a "main line" of evolutionary progress that hides a complex historical pattern, such as by the viewer assuming that taxa located on side branches are not as important as those on the central trunk [14]. While trees may live a long time, research in the learning sciences suggests that if time is not explicitly made a part of a diagram, a viewer's sense of the scale of evolutionary time may become blurred [16]. Many viewers pay more attention to the branches of tree diagrams rather than the key branch points that result in the formation of new taxa, thus leading to an overemphasis on evolution within lineages rather than via branching events [17]. Finally, the placement of names on a tree can also be problematic: multiple names along a branch may afford viewers the impression of known continuity between ancestral and descendant species, when such a line actually represents a hypothesized relationship via many generations of reproduction [17], while names at the tips of branches imply that evolutionary units are clearly-defined entities with fixed characteristics, rather than populations whose characteristics change over time [18].

Contemporary science communication researchers have used digital visualization tools to create interactive tree diagrams that enhance traditional paper-based imagery. Such diagrams may allow the user to select and zoom in on a particular branch $[19,20]$ or reorient the tree around a selected taxon [21-23]. These operations are usually targeted to help the user achieve a greater understanding of the relationships being depicted in the diagram. 
Other visualizations use animation as a narrative strategy to address tree-related misconceptions in educational settings [24]. Finally, some visualizations lead to improved information access via hyperlinking [9, 23]. Importantly, most of these interactive diagrams utilize the tree metaphor, and so may communicate some of the misconceptions common to tree-based diagrams in general.

The focus of this study is on developing a novel method of visualizing evolution as a complement to the traditional tree-related visual metaphor, and obtaining preliminary information on how this visualization is interpreted by viewers. Its purpose is to suggest a wider range of ways to communicate about the process of evolution. In place of a tree, a map metaphor is used to organize evolutionary information. Maps use proximity and direction to suggest spatial [25], linguistic [26], or logical [1] relationships. They are used widely across cultures [1], though cultural mapping conventions vary [27]. In the sciences, map-like diagrams such as Sewell Wright's adaptive landscape model for population genetics are used to communicate theory to those without mathematical expertise [28]. Therefore, the concept that a map can represent evolutionary relationships should be understandable to most viewers.

\section{Objectives}

1) To develop a new visual scientific metaphor and novel interactive visualization method for communicating evolution based on key conceptual affordances in order to overcome the limitations of existing metaphors.

2) To obtain initial feedback on how well the new interactive visualization communicates the desired key conceptual affordances to users.

\section{Methodology}

\section{The Dynamic Evolutionary Map}

In this study, key conceptual affordances of tree diagrams were identified from the literature and used to organize a novel visualization method to address conceptual limitations. A pilot evaluation was then undertaken to assess whether these affordances were being communicated. A previous publication [29] reported on the theoretical framework for this project. This paper summarizes the key affordances, reports the results of the pilot study, and discusses implications for future development. The resulting "Dynamic Evolutionary Map" (DEM) differs from traditional paper-based evolutionary diagrams by being interactive, and from interactive tree-based diagrams in using a map metaphor to visualize evolutionary pattern. Interactivity can create a sense of shared agency, engagement, and interest [30], qualities that encourage meaningful science communication. The map metaphor alters elements of tree-based diagrams that have been identified as leading to evolutionary misconceptions, and retains elements that exemplify important evolutionary theory. 


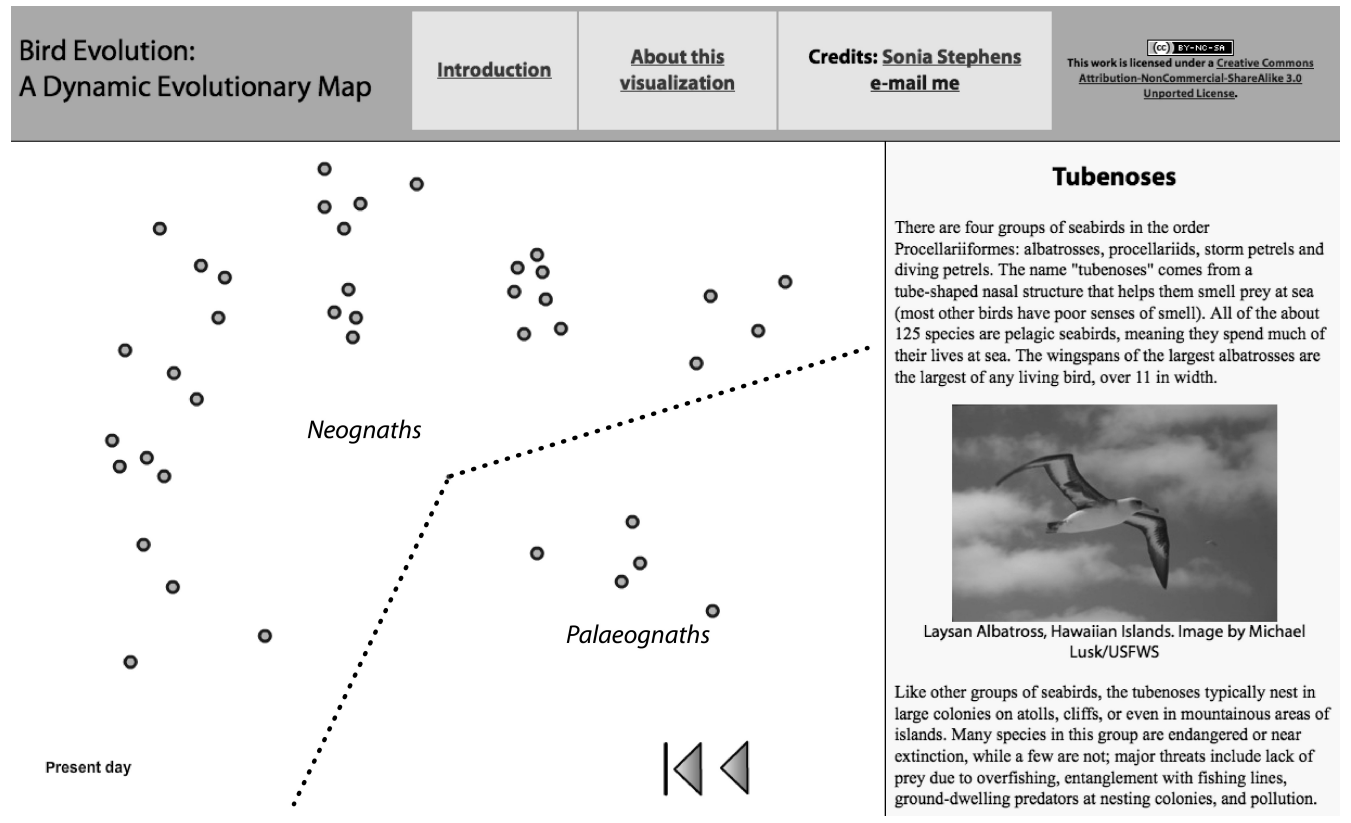

Figure 1. Screenshot of the DEM showing the present-day genetic relatedness of bird taxa. The dotted lines, which do not appear in the visualization, indicate the space allotted to the two primary avian divisions: Neognaths and Paleognaths. Dots represent the 40 taxa.

The DEM visualizes the evolution of major avian taxa from the origin of anatomically modern birds approximately 120 million years ago to the present. It is qualitatively modeled upon a large-scale taxonomic study that differentiates among about 40 avian taxa [31]. The DEM begins by representing the origin of birds at a single point in the center of the map space. A series of animated stages depicts dots representing taxa radiating out from that central point and moving across the map space in nine million-year intervals until they reach their present day positions. The more genetic change a taxon has undergone from the hypothetical ancestral bird, the further it travels outward from the center of the map. One phylogenetic tree diagram [31] was used to estimate the relative amount of genetic change within taxa and suggest placement of taxa on the map in the present day. A second tree [32] was used to calibrate the branching points of taxa splitting from one another to geological time.

As is the convention, the two phylogenetic tree diagrams used to help construct the map consist of a series of bifurcating branches. In order to represent this progressive binary division and subdivision in a radial format, the DEM was constructed by allocating a bit more than half of the map space to one of the two primary avian divisions, Neognaths (most bird species), and a bit less than half to the Palaeognaths (ostriches, emus and relatives), then half of each half to the second taxonomic level, and so on. Neognaths received more than half of the space because this group is proportionately much larger than the Palaeognaths and an equal division would have resulted in crowding (Figure 1). Within the two major divisions, the positions of taxa were then determined by qualitatively 


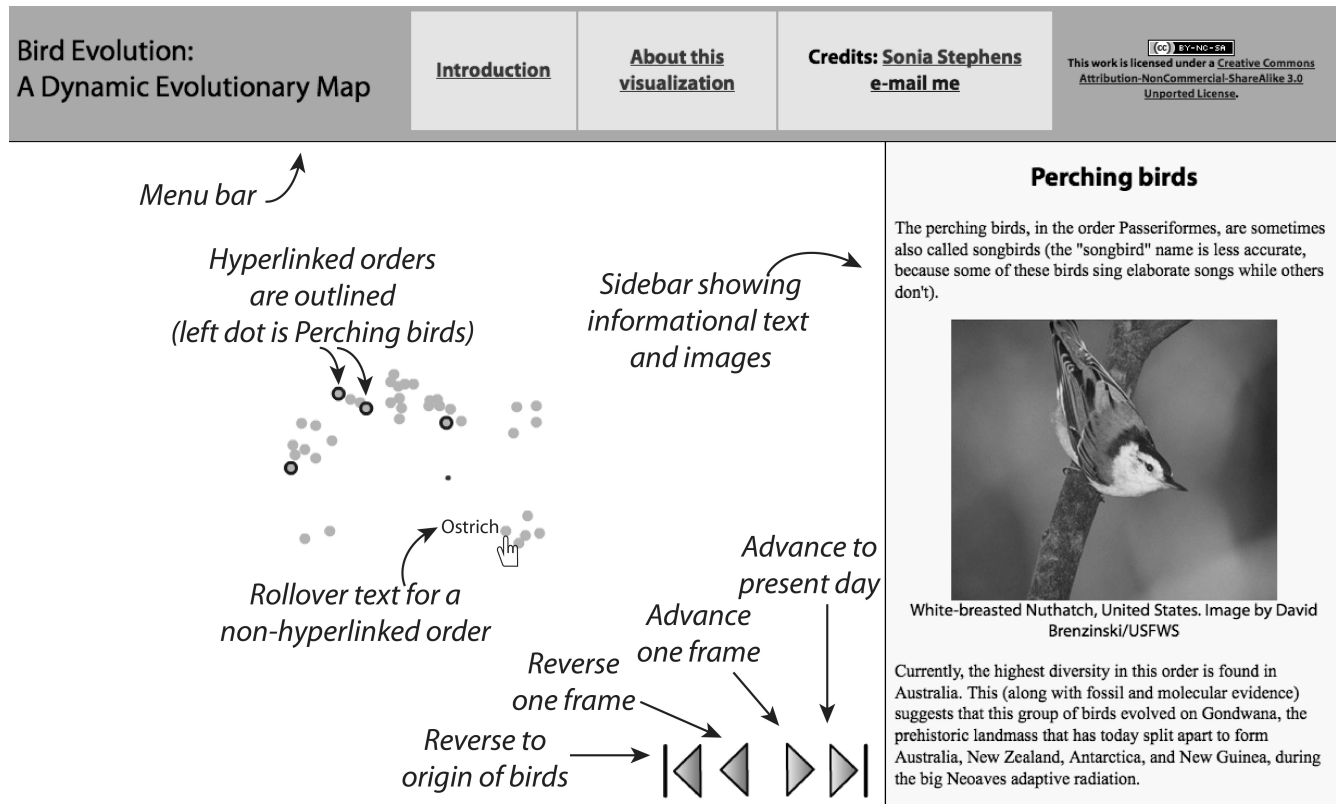

Figure 2. Screenshot of the DEM, with map features labeled.

plotting clusters of related taxa according to their genetic similarity to one another and their divergence from the origin point.

Once the present-day positions of taxa were determined, a series of 13 intermediate plots of taxa at approximately nine million-year time steps from the origin of birds was generated. The second stage in creating the DEM was to use these plots as guides to program animated, clickable dots representing the taxa onto the map space. The intermediate plots, plus the origin plot and present-day plots, were used to guide the creation of 15 total static frames that serve as stopping points during which the user can explore the positions of the taxa and interact with individual dots. Animated transitions were added between the static frames using ActionScript. The resulting dynamic map allows the user to "play" the evolution of birds forward in time in a stepped fashion.

After the animation was created, the resulting visualization was integrated into a framebased website (Figure 2). Users begin their interaction by encountering two pages describing the DEM and explaining how it works. The map can be advanced or reversed by clicking on forward and reverse buttons on the map. The visualization can be advanced or reversed either one static frame at a time (approximately nine million years in evolutionary time) or taken back to the starting point or forward to the present day with one click. During the static frames, each dot is programmed with rollover text that shows the name of the taxon when a cursor is positioned over it, thus helping the user orient themselves to the evolutionary pattern as a whole. Some of the dots are programmed with further interactivity, and may be clicked to open an informational page about the group in a sidebar.

The structure of the visualization gives users flexibility in exploring avian evolution over time. For example, users may choose to simply move backward and forward in 
time and observe the pattern of differentiation of taxa. They may also choose to follow a single taxon or group of taxa over time and observe its evolution relative to its closest relatives, thus getting a sense of relative evolutionary change and differentiation within groups. Finally, the static frames provide a way to compare the relative position of taxa at periods in history. The present-day frame in particular serves as a point of comparison, and includes a description of each taxon and photos of species so that they can be visually compared (Figure 1). The DEM is viewable here: http://goo.gl/bfMN40 (shortened link).

\section{Dynamic Evolutionary Map affordances}

Traditional tree-based diagrams communicate a range of conceptual affordances about evolution to their readers. The user evaluation of the DEM was designed to determine whether several of these predicted affordances were communicated in different ways.

First, the DEM avoids several elements of tree-based diagrams that can foster teleological misconceptions. A tree growing upward implies progress, improvement, and directionality. In the DEM, groups radiate from the center without a predominant direction of movement, thus there is no "main line" of evolution [18]. Tree diagrams may also suggest hierarchical misconceptions by differentially emphasizing some groups (e.g., placing groups above others or labeling some groups and not others) and larger taxa [16]. These elements are avoided in the DEM by including similar amounts of detail about groups, such as by labeling all taxa with rollover text and highlighting each taxon with additional information at least twice.

Second, shared descent with modification is communicated in the DEM by the movement of dots that branch from a central origin, and then move radially across the map space. This contrasts with tree diagrams, in that the key evolutionary connection between groups is movement-based, rather than persistent [17].

Third, evolution by branching events and evolution within lineages are communicated by movement. Dots splitting and moving apart show branching events, and the radial motion of dots shows evolution within a lineage. As with shared descent, affordances occur as the viewer interacts with the visualization. Branching events are key to evolutionary understanding, and static trees may not depict them well [16].

Fourth, the sense of time passing may become blurred in tree diagrams if the temporal meaning of the vertical dimension is not made explicit [16]. In the DEM, time's passage is directly seen as the viewer advances or reverses through the animation, thus making the temporal dimension apparent.

Fifth, the nature of the ancestor-descendant relationship in evolution is difficult to depict in tree diagrams [18]. In the DEM, this relationship is communicated by the continuity of dots across the map space (i.e., as the user moves forward in time, the dots move across the map as they diverge genetically from their previous state). In trees, viewers see a set of taxa connected by branch points representing hypothetical common ancestors. This may result in a misreading of the meaning of branches as representing a static group rather than an evolving lineage [17]. While the DEM uses dots instead of branches, 
the dots look the same as time passes. This may suggest that avian taxa represent an unchanging group, rather than an evolving lineage.

Sixth, because the underlying metaphor of this visualization was modified from a tree to a map, there is the possibility that users might conflate distance on the map with distance in the real world. Along with assessing whether the other predicted affordances were actually being communicated by the map, the user evaluation also explored whether map-related misconceptions were being communicated to users.

\section{Evaluation of the visualization}

In a pilot study, the DEM was evaluated to assess how the visualization communicates the key theoretical affordances described in the previous section. Nineteen undergraduate students at a U.S. university performed a series of tasks using the DEM. As they completed each task, they answered questions designed to elicit information about the affordances that the visualization was communicating to them. Questions were designed to solicit answers that indicated the participants' underlying evolutionary reasoning, which were adapted from concept categories in [33] (Table 1). Before beginning the evaluation, participants were asked several questions about their level of understanding of evolution and of birds. They were directed to interact with the DEM in several stages in order to direct their attention toward specific features.

Fourteen participants used paper-based instructions for the evaluation. Because responses suggested that participants focused more on the text elements of the visualization than the DEM itself, a second verbally-directed evaluation through the same type of tasks and questions was conducted with five additional participants: participants were verbally asked a question about the map, and directed to use the map to answer the question. They were told to focus on the map part of the visualization, although they could use the text to help them answer the questions.

Paper-based participants were given one hour to complete the questionnaire; verballydirected participants generally completed the evaluation in slightly less time. Participants performed these tasks: read introductory information, answered questions about Palaeognaths, compared Palaeognaths and Neognaths, answered questions about specific groups across the map space, and gave feedback about the overall design of the map. In both evaluations, a small number of participants requested verbal clarification from the author, who was present in the testing room, on where to find specific extinct groups and why only some dots were hyperlinked.

Participant responses were coded by the author for presence or absence of language that indicated that participants were reasoning using evolutionary concepts associated with six categories of conceptual affordances (adapted from concept categories in [33]): teleological judgments, evolutionary comparisons, evolutionary processes, branching events versus evolution within a lineage, time, and geographical location. Table 2 describes the criteria used to code responses into categories. In general, different questions elicited different types of responses, so different categories applied to different questions. 
Table 1. Questions asked during the evaluation.

\begin{tabular}{|c|c|c|}
\hline Question & $\begin{array}{l}\text { Paper- } \\
\text { based }\end{array}$ & $\begin{array}{l}\text { Verbally- } \\
\text { guided }\end{array}$ \\
\hline $\begin{array}{l}\text { How would you describe what has happened to this group of birds (Palaeognaths) } \\
\text { over time to the present day, in your own words? }\end{array}$ & $\mathrm{X}$ & $\mathrm{X}$ \\
\hline $\begin{array}{l}\text { How did these two groups of birds (Palaeognaths and Neognaths) arise, in your own } \\
\text { words? }\end{array}$ & $\mathrm{X}$ & $\mathrm{X}$ \\
\hline $\begin{array}{l}\text { Do these two groups (Palaeognaths and Neognaths) seem to have the same number } \\
\text { of descendant groups that have survived to the present day? Based on what you } \\
\text { learned from the map, why is (or isn't) this the case? }\end{array}$ & $\mathrm{X}$ & $\mathrm{X}$ \\
\hline $\begin{array}{l}\text { Click through the animation until you reach the present day. In your own words, } \\
\text { low do you describe what is being represented on the screen? }\end{array}$ & $\mathrm{X}$ & $\mathrm{X}$ \\
\hline For orders that are close together, what type of similarity is being displayed? & & $\mathrm{X}$ \\
\hline $\begin{array}{l}\text { Can you find any examples of birds that are anatomically similar but far away from } \\
\text { one another on the map? How would you explain this, using the map? }\end{array}$ & & $\mathrm{X}$ \\
\hline How would you describe the relationship between the Ostriches and the Tinamous? & $\mathrm{X}$ & $\mathrm{X}$ \\
\hline $\begin{array}{l}\text { Based on the map, which of these pairs of groups are more closely related: } \\
\text { Flamingos and Land Fowl, or Land Fowl and Waterfowl (Ducks + Geese + Swans)? } \\
\text { Why do you think so? }\end{array}$ & $\mathrm{X}$ & $\mathrm{X}$ \\
\hline $\begin{array}{l}\text { Based on the map, how long ago did the Cuckoos+relatives and Penguins last share } \\
\text { a common ancestor? (Hint: these groups are found in the top right.) }\end{array}$ & $\mathrm{X}$ & \\
\hline $\begin{array}{l}\text { How would you describe the relationship between the Seriemas and the extinct } \\
\text { Terror Birds (paper evaluation) or Tinamous and the extinct Moas (verbal } \\
\text { zvaluation)? }\end{array}$ & $\mathrm{X}$ & $\mathrm{X}$ \\
\hline $\begin{array}{l}\text { Do any bird orders seem more advanced than others? Why or why not? If so, which } \\
\text { ones? }\end{array}$ & $\mathrm{X}$ & $\mathrm{X}$ \\
\hline $\begin{array}{l}\text { Do any bird orders seem more similar to dinosaurs than others? Why or why not? If } \\
\text { so, which ones? }\end{array}$ & $\mathrm{X}$ & $\mathrm{X}$ \\
\hline What happened to the original ancestral bird species? & $\mathrm{X}$ & $X$ \\
\hline $\begin{array}{l}\text { Did using the evolutionary map change your understanding about bird evolution? If } \\
\text { so, how? (A sentence or two is fine). }\end{array}$ & $X$ & $X$ \\
\hline $\begin{array}{l}\text { Do you have any general comments about your experience with using the map (e.g., } \\
\text { was anything confusing or surprising)? }\end{array}$ & $X$ & $X$ \\
\hline
\end{tabular}

However, many responses also included language associated with more than one concept category (i.e., one response might refer to multiple concepts, such as both evolutionary processes and time). Within each of these categories, responses were coded according to the nature of the explanation given for the participant's reasoning.

\section{Results}

There were 14 participants in the paper-based part of the evaluation (seven male, five female), and five in the verbally-directed part (two male, three female). Additional information was collected for the paper-based evaluation, but not during the follow-up verbally 
Table 2. Conceptual categories and types of participant responses.

\begin{tabular}{|c|c|c|}
\hline Concept category & Criteria & Type of response \\
\hline $\begin{array}{l}\text { Teleological } \\
\text { judgments }\end{array}$ & $\begin{array}{l}\text { Responses that included teleological } \\
\text { references were coded according to } \\
\text { the basis upon which primitive or } \\
\text { advanced characteristics were } \\
\text { inferred. }\end{array}$ & $\begin{array}{l}\text { a) based on location on the map } \\
\text { b) based on physical description or images } \\
\text { c) based on diversity or rate of evolution } \\
\text { d) no difference/unable to tell }\end{array}$ \\
\hline $\begin{array}{l}\text { Evolutionary } \\
\text { comparisons }\end{array}$ & $\begin{array}{l}\text { Responses that explicitly compared } \\
\text { two or more groups of birds were } \\
\text { categorized according to the nature } \\
\text { of the evolutionary relationship. }\end{array}$ & $\begin{array}{l}\text { a) ancestor/descendant or common ancestor } \\
\text { b) evolving to/from, or through a transition stage } \\
\text { c) relatives / related (not further specified) } \\
\text { d) belong to the same/different group on map (not } \\
\text { further specified) } \\
\text { e) have similar/different physical characteristics } \\
\text { f) can't determine relationship }\end{array}$ \\
\hline $\begin{array}{l}\text { Evolutionary } \\
\text { processes }\end{array}$ & $\begin{array}{l}\text { Responses that included references } \\
\text { to evolutionary processes without } \\
\text { making explicit comparisons } \\
\text { between groups were categorized by } \\
\text { the evolutionary pattern or causal } \\
\text { mechanism being described. }\end{array}$ & $\begin{array}{l}\text { a) genetic causes (evolution via mutation) } \\
\text { b) environmental causes (e.g., role of environment or } \\
\text { human influence) } \\
\text { c) geographic causes (i.e., because of location) } \\
\text { d) directional or purposeful change (e.g., filling } \\
\text { niches, avoiding predators) } \\
\text { e) loss or acquisition of a trait (no causal mechanism) } \\
\text { f) generic processes (e.g., speciation, splitting or } \\
\text { diverging, fitness) } \\
\text { g) extinction } \\
\text { h) simple description of pattern (no causal } \\
\text { explanation or sophisticated terminology) }\end{array}$ \\
\hline $\begin{array}{l}\text { Branching events } \\
\text { versus evolution } \\
\text { within a lineage }\end{array}$ & $\begin{array}{l}\text { Responses that explicitly mentioned } \\
\text { evolution by branching events or } \\
\text { change within a group. }\end{array}$ & $\begin{array}{l}\text { a) evolution via branching events } \\
\text { b) evolution within a lineage }\end{array}$ \\
\hline Time & $\begin{array}{l}\text { Responses that explicitly mentioned } \\
\text { time. }\end{array}$ & $\begin{array}{l}\text { a) generic (e.g., over time, earlier/later) } \\
\text { b) specific (references to years or events in the map } \\
\text { timeline) }\end{array}$ \\
\hline $\begin{array}{l}\text { Geographical } \\
\text { location }\end{array}$ & $\begin{array}{l}\text { Responses that mentioned } \\
\text { geography as a defining } \\
\text { characteristic of a group or groups. }\end{array}$ & (not differentiated) \\
\hline
\end{tabular}

directed evaluation; those participants were of similar age to the first group. Most participants (nine out of 14) had taken high school biology plus an introductory college biology course, three had taken only high school biology, and two reported taking both introductory and advanced college courses. The mean number of years since taking a biology course was $3.2(\mathrm{SD}=5.0)$; five participants were currently taking a biology course, five took one within the last two years, and four took biology between four and 17 years ago. On a scale of one to 11 (with one indicating no knowledge and 11 being expert), participants ranked their understanding of birds a mean of $3.6(\mathrm{SD}=2.0)$, and their understanding of evolution a mean of $2.4(\mathrm{SD}=1.5)$. Most students were English, technical writing, and computer science majors; other majors were biology and interdisciplinary studies.

\section{Teleology}

Figure 3 shows responses to one question designed to elicit information about the nature of teleological misconceptions ("Do any bird orders seem more advanced than others? Why or why not? If so, which ones?"). This question was designed to get participants to think about what constituted their criteria for advancement and reveal how these ideas interacted with the DEM. In the paper-based evaluation, teleological concepts were about 


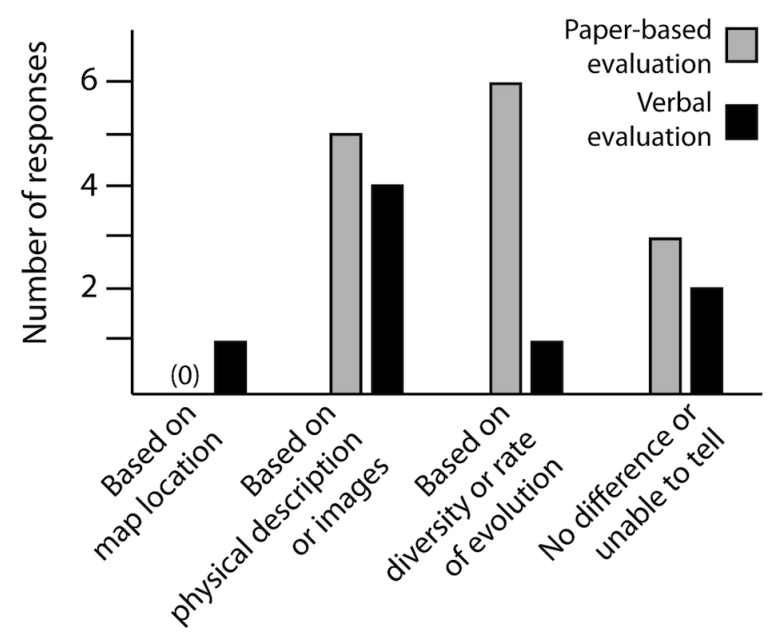

Figure 3. Reasons given to support teleological judgments. (Some responses included multiple types of reasoning.)

evenly associated with birds' physical features and the diversity of the major groups (e.g., a group with more taxa was more "advanced"). In the verbal evaluation, most reasons were based on physical features. A few participants were uncertain how to define "advanced." Information about physical features would have been obtained from the visualization's text and images, while information about diversity could have been gained from text or the DEM. Verbally directed participants took much less time to read the text, but still largely based their ideas about "advancement" on the physical descriptions of birds, rather than on the differential diversity of different areas of the map.

These results suggest that at least some of the teleological affordances found in tree diagrams may not be found in the DEM. The idea that evolution is purposeful and directed is a widespread misconception [15], though whether participants already held teleological misconceptions was not directly tested in this study. In response to another question about which birds seemed more dinosaur-like, several participants referred to physical features like large size, predatory nature, and flightlessness that they may associate with dinosaurs. It also appears that the map metaphor itself did not contribute strongly to these misconceptions. For example, only one participant used distance on the map from the origin of birds to support ideas about advancement, which suggests that users largely did not connect map distance or proximity to the original ancestral bird with "advancement."

\section{Shared descent}

The DEM depicts the pattern of shared descent through the animation of dots across the map space. In general, results suggest that participants had few problems recognizing that the movement of dots was indicative of the biological relationships of the taxa that they represented. Table 3 summarizes the responses to several questions designed to elicit in- 
Table 3. Participant assumptions about the evolutionary processes and relationships being displayed in the DEM.

\begin{tabular}{|c|c|c|c|c|c|c|c|c|c|c|c|c|c|c|c|}
\hline \multirow{4}{*}{\begin{tabular}{|l}
\multicolumn{1}{|c|}{ Question } \\
How would you describe what \\
has happened to this group of \\
birds (Palaeognaths) over time \\
to the present day, in your own \\
words?
\end{tabular}} & & \multicolumn{6}{|c|}{ Evolutionary comparisons } & \multicolumn{8}{|c|}{ Evolutionary processes } \\
\hline & & a & $\mathrm{b}$ & c & d & e & $\mathrm{f}$ & $\mathrm{a}$ & $\mathrm{b}$ & c & d & $\mathrm{e}$ & $\mathrm{f}$ & $\mathrm{g}$ & $\mathrm{h}$ \\
\hline & $\begin{array}{r}\text { Paper } \\
\text { evaluation }\end{array}$ & - & - & - & - & 2 & - & 3 & 5 & 1 & 1 & 7 & 9 & 1 & 1 \\
\hline & $\begin{array}{r}\text { Verbal } \\
\text { evaluation }\end{array}$ & 1 & 1 & - & 1 & 1 & - & - & 1 & - & 1 & 1 & 3 & - & - \\
\hline \multirow{2}{*}{$\begin{array}{l}\text { How did these two groups of } \\
\text { birds (Palaeognaths and } \\
\text { Neognaths) arise, in your own } \\
\text { words? }\end{array}$} & $\begin{array}{r}\text { Paper } \\
\text { evaluation }\end{array}$ & 2 & 7 & - & - & 6 & - & - & 2 & 1 & 1 & - & 5 & - & 1 \\
\hline & $\begin{array}{r}\text { Verbal } \\
\text { evaluation } \\
\end{array}$ & 1 & 1 & - & - & - & - & - & - & - & - & - & - & - & - \\
\hline $\begin{array}{l}\text { Do these two groups } \\
\text { (Palaeognaths and Neognaths) } \\
\text { seem to have the same number } \\
\text { of descendant groups that have } \\
\text { survived to the present day? }\end{array}$ & $\begin{array}{r}\text { Paper } \\
\text { evaluation }\end{array}$ & 4 & 3 & - & - & 3 & - & 1 & 4 & - & 1 & 1 & 5 & - & 5 \\
\hline $\begin{array}{l}\text { Based on what you learned } \\
\text { from the map, why is (or isn't) } \\
\text { this the case? }\end{array}$ & $\begin{array}{r}\text { Verbal } \\
\text { evaluation }\end{array}$ & - & - & - & - & - & - & - & 1 & - & - & - & 4 & - & - \\
\hline $\begin{array}{l}\text { Click through the animation } \\
\text { until you reach the present day. } \\
\text { In your own words, how do } \\
\text { you describe what is being } \\
\text { represented on the screen? }\end{array}$ & $\begin{array}{r}\text { Verbal } \\
\text { evaluation }\end{array}$ & 1 & 1 & - & 1 & 1 & - & - & 1 & - & 1 & 1 & 3 & - & - \\
\hline \multirow{2}{*}{$\begin{array}{l}\text { How would you describe the } \\
\text { relationship between the } \\
\text { Ostriches and the Tinamous? }\end{array}$} & $\begin{array}{r}\text { Paper } \\
\text { evaluation }\end{array}$ & 1 & 3 & 1 & 1 & 2 & 1 & - & - & - & - & - & - & - & - \\
\hline & $\begin{array}{r}\text { Verbal } \\
\text { evaluation } \\
\end{array}$ & - & - & 1 & - & - & 5 & - & - & - & - & - & - & - & - \\
\hline $\begin{array}{l}\text { Based on the map, which of } \\
\text { these pairs of groups are more } \\
\text { closely related: Flamingos and }\end{array}$ & $\begin{array}{r}\text { Paper } \\
\text { evaluation }\end{array}$ & 1 & 5 & 2 & 8 & 7 & - & - & - & - & - & - & - & - & - \\
\hline $\begin{array}{l}\text { Land Fowl, or Land Fowl and } \\
\text { Waterfowl (Ducks + Geese }+ \\
\text { Swans)? Why do you think so? }\end{array}$ & $\begin{array}{r}\text { Verbal } \\
\text { evaluation }\end{array}$ & - & 3 & - & 3 & - & - & - & - & - & - & - & - & - & - \\
\hline $\begin{array}{l}\text { How would you describe the } \\
\text { relationship between the } \\
\text { Seriemas and the extinct Terror }\end{array}$ & $\begin{array}{r}\text { Paper } \\
\text { evaluation }\end{array}$ & 1 & - & 4 & 2 & 2 & 6 & - & - & - & - & - & - & - & - \\
\hline $\begin{array}{l}\text { Birds (paper evaluation) or } \\
\text { Tinamous and the extinct Moas } \\
\text { (verbal evaluation)? }\end{array}$ & $\begin{array}{r}\text { Verbal } \\
\text { evaluation }\end{array}$ & - & 1 & 2 & 2 & 3 & - & - & - & - & - & - & - & - & - \\
\hline
\end{tabular}

Evolutionary comparisons: $a=$ ancestor/descendant or common ancestor; $b=e v o l v i n g$ to/from, or through a transition stage; $c=$ relatives/related (not further specified); $d=$ belong to the same/different group on map (not further specified); e=have similar/different physical characteristics; $\mathrm{f}=$ can't determine relationship.

Evolutionary processes: $a=$ genetic causes; $b=$ environmental causes (e.g., role of environment or human influence); $c=$ geographic causes; $d=$ directional or purposeful change (e.g., filling niches, avoiding predators); $\mathrm{e}=$ loss or acquisition of a trait (no causal mechanism); $\mathrm{f}=$ generic processes (e.g., speciation, splitting or diverging, fitness); $\mathrm{g}=$ extinction; $\mathrm{h}=$ simple description of pattern (no causal explanation or sophisticated terminology). 
formation about participants' assumptions about the evolutionary processes and relationships being displayed. Two types of responses indicated a sophisticated understanding of evolution (evolutionary comparisons specifying an ancestor/descendant relationship or common ancestor, and evolutionary change specifying genetic causes), while all other responses suggested a less sophisticated understanding [16].

In the paper-based evaluation in particular, participants made relationship assumptions based upon accompanying text and images instead of (or along with) the DEM itself. For example, when asked to interpret the overall pattern of animation while focusing on the Palaeognath group, most of the responses included some combination of terms describing splitting or adapting plus a physical trait or traits; e.g., "This group of birds split into three different species including some flightless birds which are classified partly by their lack of keeled breastbones." The reliance on text and images by the paper-based group motivated addition of the verbally-directed evaluation. While it is difficult to make inferences from only five participants, results suggest that the second group of participants relied more on the DEM than on text and images.

Participants' reliance on text and images rather than the DEM was also seen in responses to questions about relationships between two different groups of birds, one group an extinct taxon and the second group the closest living relative of that taxon. This question seemed confusing to several participants who had difficulty finding the extinct taxon, because the information about the extinct group was obtained by clicking on the dot corresponding to the modern taxon at the appropriate point in the timeline (e.g., Terror Birds are found on the Seriema dot about 50 million years ago). Participants could have found the correct answer either in the text or by inference based upon the fact that both groups were described by the same dot. Many responses, however, were based on comparisons of the physical traits of the groups. This question was designed to determine in part whether users would assume that the extinct groups were the direct ancestors of the modern groups, a possibility because they came before them on the same dot. Only two participants (one from each evaluation) gave this response. These results suggest that while users understood the overall pattern of shared descent (e.g., groups splitting from other groups), the ancestor-descendant aspect of evolution was not clear in the DEM.

\section{Evolution via branching events vsévolution within a lineage}

For coding purposes, references to branching events and within-lineage evolution were summarized across all responses (these responses included references coded into both the "evolutionary comparisons" and "evolutionary processes" categories of table 2). References to evolution via branching events (e.g., splitting, branching) appeared in about $13 \%$ of responses, and references to evolution within a lineage (e.g., adaptation, evolution, change) appeared in about $29 \%$ of responses (Figure 4). Branching events are particularly important in that they describe how different biological groups form. Previous research suggests that non-tree based evolutionary diagrams do not suggest branching to students, and may therefore be less suitable for communicating about evolution [16]. The 


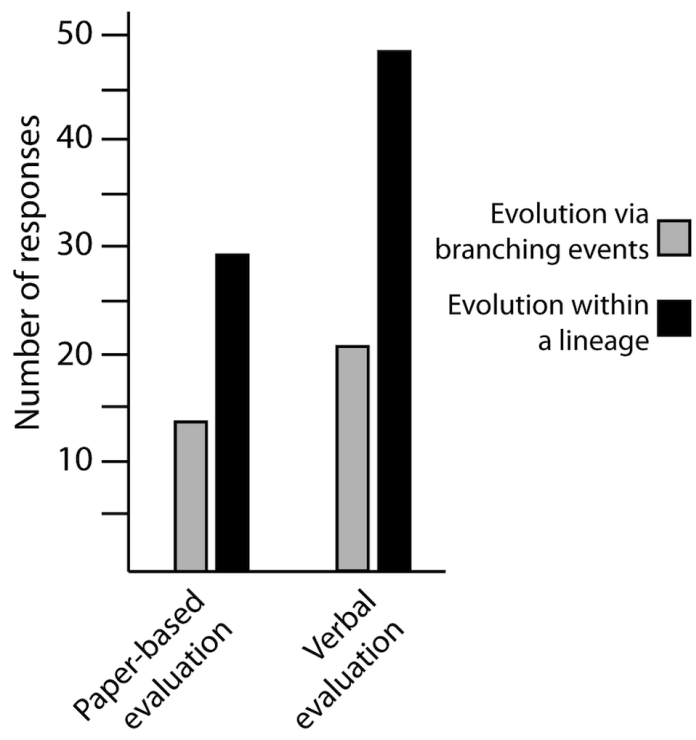

Figure 4. Usage of terms in all responses that were associated with evolution via branching events or evolution within a lineage.

results of this study suggest that participants were using the DEM to support both types of evolutionary pattern, at least to some extent. An example response that supports this is "The map clearly shows that the Neognath group diverged into many other groups, while the Palaeognath group had five diverging groups." Nevertheless, such comments were only found in a minority of responses, suggesting that the DEM may not be suggesting these affordances to viewers as strongly as it could be.

Because this study did not make explicit comparisons between the DEM and a tree diagram, it is difficult to make broader generalizations about the magnitude of these responses, as compared to their prevalence in research on trees. Importantly, nearly all of the participants used branching movement, rather than the final proximity of dots, to evaluate relatedness among taxa. For example, in response to a question about which two of three specific taxa were most closely related, a majority (64\%) based their answers at least in part upon the pattern of animation on the map. As with shared descent, these results suggest that the movement of dots was helpful in visualizing relationship patterns.

Time

Another question of interest was how well the DEM would convey the concept of time. For coding purposes, temporal references were summarized across all responses. Participants largely were aware of the passage of time, as indicated by many temporal references (65 non-specific references and 21 references to exact dates). No timeline was displayed in the visualization, which made it difficult to tie this awareness to an accurate understanding of exact dates. When asked to date a specific event in the visualization that took 


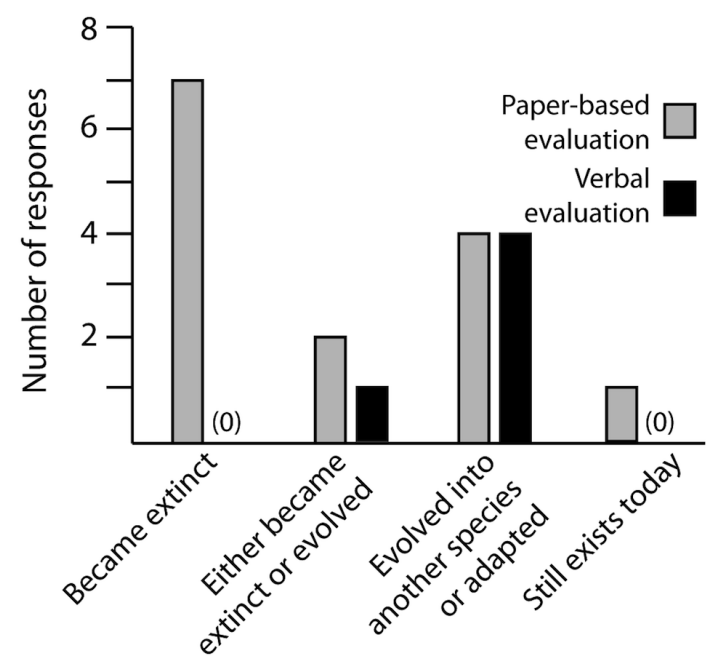

Figure 5. Responses to the question: "What happened to the original ancestral bird species?" (One participant left this question blank.)

place about 65 million years ago, all but one participant were able to give an exact date for this event. However, six of the eighteen dates were incorrect (e.g., based on the ages of fossils described in the text).

\section{Ancestor-descendant relationships}

Participant responses suggest that individuals largely viewed taxa as individual units rather than as collections of individuals with ancestor-descendant relationships (Table 3). The ancestor-descendant aspect of evolution may have been unclear; e.g., participants may have had the misconception that avian groups remain fundamentally the same over time. That is, the "ostrich" dot 80 million years ago might be assumed to represent the same species that exists in the present, though it is scientifically accurate to say that the earlier dot represents the ancestors of the modern ostrich.

One question asked, "What happened to the original ancestral bird species?" Several answers suggested that the original bird species either became extinct or evolved (Figure 5). One respondent said that it still exists today, and another was unsure. Answers largely suggested a view of evolution in which the subjects of evolution, species, are seen as individuals rather than as loose populations of individuals. The species-as-individual view of evolution may create a sense of historical closure, which may foster a teleological view of evolution [14]. Very few responses suggested a sophisticated view of evolutionary subjects as ancestor-descendent lineages. One exception is a response stating: "The ancestor of the modern birds survived the Cretaceous-Tertiary mass extinction. It is questionable which is the original ancestral bird species. There are birds and bird-like dinosaur ancestors." 


\section{Map-related misconceptions}

One of the concerns with modifying the underlying evolutionary metaphor to a map was that users might conflate distance on the DEM with real-world distance, or connect the movement of the dots on the DEM with real-world spatial movement. For coding purposes, geographical references were summarized across all responses. Only three responses (two from the same participant) explicitly mentioned real-world locations or directly connected the movement of birds with the movement of the dots in the virtual evolutionary space (e.g., "The Palaeognaths evolved more slowly. Not as many birds relocated to that particular area.") This suggests that the map-based visualization might not introduce new spatially based misconceptions to users.

\section{Conclusions}

Because metaphors help us make connections between familiar domains of understanding and new ideas, metaphor plays an important role in science communication and the public understanding of science [12]. The DEM was designed to address some of the misconceptions that the metaphoric affordances of the tree of life suggest to viewers of tree-like visualizations of evolution. It illustrates the genetic distance among avian taxa on a metaphoric map-like space of evolutionary adaptation, and shows viewers how taxa have moved across that virtual space as they have differentiated from their ancestors over time. The intent of this project is to demonstrate a communication method complementary to phylogenetic trees.

Most interactive evolution visualizations emphasize understanding phylogenetic trees [21-23] and may therefore not help users overcome tree-based misconceptions [20]. In general, results of this pilot user evaluation suggest that the DEM communicates some conceptual affordances differently than tree visualizations. However, this study has important limitations. First, no direct comparisons were made to an interactive tree diagram with similar properties, which would clarify whether the results were due to the map structure or another feature such as interactivity. Second, the number of participants was small, and two different methods of questioning (paper-based and verbal) were used to present the evaluation questions. Third, participants relied upon the text and images in the sidebar of the visualization to support their responses more strongly than expected, particularly in the paper-based evaluation. Nevertheless, participant responses can be used to suggest preliminary support to the theoretical predications, as well as aspects of the DEM that might be improved in the future so as to better communicate desired conceptual affordances.

\section{Concepts the DEM may communicate well}

As user feedback suggests, the DEM may be better at communicating some affordances for evolutionary understanding than many tree diagrams. For example, several elements in 
tree diagrams may suggest upward progress, direction, or teleological evolution $[14,15]$. The DEM's radial pattern avoids communicating the directional and hierarchical aspects of tree growth that may be found in tree-based diagrams. It also avoids differential resolution of parts of the diagram by labeling all groups with rollover text and highlighting each group with additional information at least twice. The user evaluation suggests that the DEM did not suggest common tree-associated teleological concepts to the participants. However, participants used sidebar images and text to support their existing notions of "primitiveness" (e.g., flightlessness), suggesting that this may have been a confounding factor.

One interesting result is that several participants associated "advancement" with a group of birds that diversified more over time (Neognaths) than did another group (Paleognaths). Participants were explicitly asked to look for "advancement" in the DEM, and focused upon the branching pattern of descent in the diagram. While this indicates that participants used the DEM to support an evolutionary misconception when prompted to do so, it also suggests that the DEM was being interpreted correctly with regards to the concept of shared descent. Tree-based diagrams suggest shared descent by the overall structure of the tree connecting different groups [34], while the DEM visualizes it via the branching pattern of movement. In the DEM the linkage between groups is ephemeral, and based on movement rather than a persistent visual connection. Participants appeared to have few problems interpreting the meaning of splitting and moving dots, though their responses largely did not suggest a sophisticated understanding of the underlying evolutionary mechanisms. Notably, nearly all of the participants used branching, rather than the final proximity of dots, to evaluate the degree of relatedness between taxa.

The temporal dimension is another key aspect of evolution. Tree diagrams may be interpreted as showing either the evolving pattern of life over time, or as showing a hierarchical arrangement of groups within a single time period. In other words, the sense of time passing that the tree is meant to convey may become blurred [16]. Time is incorporated into the DEM as viewers advance through the animation, making this aspect of evolution easy for viewers to visualize. There is no continuous visual reminder of the time scale, however, and participants in this study had difficulty identifying the timing of specific events. Incorporating a timeline could clarify this concept.

\section{Concepts the DEM may not communicate well}

Other evolutionary affordances may not be communicated better by the DEM. In treebased diagrams, evolution via branching events and evolution within a lineage are suggested by branch points and growth of the limb from the branch point, respectively. In many tree diagrams, both of these processes may be obscured by the details of the illustration [14], so the key splitting events may not be apparent [16]. In the DEM, the movement of dots splitting apart and then across the map space represents these evolutionary patterns. While the splitting movement might draw attention more readily than a static branch pattern, in this study there were about twice as many references to evo- 
lution within a lineage than to branching events in responses. Adding a visual feature that calls attention to splitting events, such as changing the color of dots, might better communicate their importance.

Similarly, the nature of ancestor-descendent relationships is difficult to convey in diagrams: the evolutionary unit is a population, and readers of diagrams tend to interpret representations of populations (e.g., by lines or dots) as individuals [18]. Study responses suggested that taxa were being interpreted as though they were individuals, rather than ancestor-descendant lineages. To better communicate the changing nature of groups over time, dots might be programmed to change color or shape as time passes. However, this may also overemphasize evolution within lineages as compared to splitting events, so these features of the map would need to be evaluated carefully.

The causal forces that shape evolutionary pattern are not well represented in either evolutionary trees or the DEM, because both focus on evolutionary pattern itself. Because the DEM's visual elements did not suggest the causes of groups differentiating, participants likely relied on a combination of their previous understanding of evolution and the visualization text to infer causal mechanisms. In general, participant responses did not suggest a sophisticated view of evolutionary processes and largely focused on describing the overall pattern of the DEM. To better communicate these processes, the DEM could be modified or supplemented to include a focus on fine-scale evolutionary drivers.

Participant responses did not suggest a high level of map-related misconceptions, such as conflating spatial movement of the dots that move across the map space with movement across the real-world landscape. The map metaphor might not be explicit enough for novices to entangle the affordances of maps with those of the visualization, or novices might be familiar enough with the conventions of non-spatial mappings that they do not assume that the visualization represents real-world geography. Nevertheless, this possibility cannot be ruled out because of the small sample size.

Two additional aspects of the DEM may not communicate evolutionary concepts well. First, the map represents genetic similarity with physical proximity. Responses did not clarify how well users interpreted this feature. Participants largely based their explanations of similarities and differences among taxa on the pictures and descriptions of the birds, rather than on the map. This suggests that participants recognized that the proximity of dots was related to the relationships of taxa, but the text and images seemed to be more appealing as a source of explanation than the map itself. This issue could be resolved by reducing the amount of sidebar text and images in future development. Second, tree diagrams may be better at facilitating specific comparisons based upon shared descent, because the map uses animation rather than a static branching pattern to which a user can refer. Comparative testing might help elucidate whether a persistent image is better than motion for depicting a pattern in this situation.

\section{Future research}

The DEM modifies a conventional visual metaphor for evolution, the "tree of life," rather than making the conventional metaphor interactive. This does not oppose the DEM to 
other methods of visualization, but is designed as a complementary approach. While other research projects primarily work within the tree-like tradition, the DEM presents an alternative interpretation of evolutionary pattern that appears to support evolutionary understanding among its users.

Communicating about science in multiple media, formats, and metaphoric frameworks provides a variety of intellectual and affective affordances to which viewers might make connections. For example, the DEM provides a hands-on tool that could be introduced to museums or disseminated online in order to engage the public in exploring how evolutionary pattern develops over time, thus emphasizing the temporal element that is missing from many static tree diagrams. In educational settings, the DEM could be incorporated into current teaching practice, which includes learning how to interpret phylogenetic trees. The DEM might be introduced to accompany tree diagrams and other types of visualizations that support evolution teaching.

This visualization method also suggests possibilities for communication about of biological data within the sciences by using an alternative to the tree-structure that underpins other evolutionary visualizations. The DEM offers a novel perspective that suggests a third dimension (via movement) in a structure that is normally viewed flattened into two dimensions (a phylogenetic tree). Such a map could enrich biologists' tree-based thinking, and help them both conceptualize and share more complex ideas about the relationships among groups of organisms.

Future planned research with the DEM involves the construction of an interactive treebased diagram that shares design similarities with the DEM. This will allow a controlled comparison to a more traditional type of visualization and help clarify the differences between the DEM and more traditional visualizations. Another future research consideration is how refining the visualization features, such as by simplifying sidebar text and images and adding a timeline, will affect the user experience. The preliminary evaluation of this project suggests that the methodological approach of constructing new visual scientific metaphors based on key conceptual affordances in order to overcome the limitations of existing metaphors has been at least partially successful in communicating evolution differently than in existing visualization methods. Future enhancement and testing of this visualization will help refine these preliminary results. There are several potential applications for this visualization for informal science communication and formal education. Moreover, the approach suggested in this project can potentially be extended into other areas of science communication. As such, the DEM suggests a novel approach to designing future science visualizations.

\section{References}

[1] B. Tversky (2005), "Prolegomenon to Scientific Visualizations", in J. K. Gilbert ed., Visualization in Science Education, Springer, Dordrecht, Netherlands, pp. 29-42.

[2] W.-M. Roth and M.K. McGinn (1998), "Inscriptions: Toward a Theory of Representing as Social Practice", Rev. Educ. Res. 68: 35-59. 
[3] T.E. MacDonald (2010), “Communicating Phylogeny: Evolutionary Tree Diagrams in Museums”, in proceedings of 2010 Annual International Conference - Research into Practice: Practice Informing Research, National Association for Research in Science Teaching Philadelphia, PA, U.S.A.

[4] D.A. Norman (1990), The Design of Everyday Things, Doubleday, New York, U.S.A.

[5] J. Trumbo (2006), "Making Science Visible: Visual Literacy in Science Communication”, in Luc Pauwels ed., Visual Cultures of Science: Rethinking Representational Practices in Knowledge Building and Science, Hanover, Dartmouth CP, U.S.A., pp. 266-283.

[6] P.J. Aubusson, A.G. Harrison and S.M. Ritchie (2006), "Metaphor and Analogy", in P.J. Aubusson, A.G. Harrison and S.M. Ritchie eds., Metaphor and Analogy in Science Education, Springer, Dordrecht, Netherlands, pp. 1-9.

[7] D. Gentner, S. Brem, R.W. Ferguson, A.B. Markman, B.B. Levidow, P. Wolff and K.D. Forbus, (1997), "Analogical Reasoning and Conceptual Change: A Case Study of Johannes Kepler", J. Learn. Sci. 6: 3-40.

[8] F. Maderspacher (2006), "The Captivating Coral-the Origins of Early Evolutionary Imagery", Curr. Biol. 16: R476-R478.

[9] D.A. Maddison, K.-S. Schulz and W.P. Maddison (2007), “The Tree of Life Web Project”, Zootaxa 1668: $1-766$.

[10] T.W. Pietsch (2012), Trees of Life: A Visual History of Evolution, Johns Hopkins University Press, Baltimore, U.S.A.

[11] H.E. Gruber (2005), “Darwin's 'Tree of Nature' and other Images of Wide Scope”, in H.E. Gruber and K. Bodeker eds., Creativity, Psychology and the History of Science, Springer, New York, U.S.A., pp. 241-257.

[12] M.B. Hesse (1966), Models and Analogies in Science, University of Notre Dame, Notre Dame, Indiana, U.S.A.

[13] T.R. Gregory (2012), “Understanding Evolutionary Trees”, Evolution: Education and Outreach 1: 121-137.

[14] R.J. O’Hara (1992), “Telling the Tree: Narrative Representation and the Study of Evolutionary History”, Biol. Philos. 7: 135-160.

[15] B.J. Alters and C.E. Nelson (2002), “Teaching Evolution in Higher Education”, Evolution 56: 1891-1901.

[16] K.M. Catley and L.R. Novick (2009), “Digging Deep: Exploring College Students' Knowledge of Macroevolutionary Time”, J. Res. Sci. Teach. 46: 311-332.

[17] K.M. Catley and L.R. Novick (2008), "Seeing the Wood for the Trees: An Analysis of Evolutionary Diagrams in Biology Textbooks", BioScience 58: 976-987.

[18] R.J. O'Hara (1988), "Homage to Clio, or, Toward an Historical Philosophy for Evolutionary Biology”, Syst. Zool. 37: 142-155.

[19] S.F. Carrizo (2004), "Phylogenetic Trees: An Information Visualisation Perspective", in Y.-P.P. Chen ed., Conferences in Research and Practice in Information Technology 29: 315-320.

[20] C. Matuk (2008), “Animated Cladograms: Interpreting Evolution from Diagrams”, in G. Stapleton, J. Howse and J. Lee eds., Diagrams 2008, LNAI 5223, pp. 395-397.

[21] J. Rosindell and J.L. Harmon (2012), "OneZoom: A Fractal Explorer for the Tree of Life", Public Library of Science Biology 10: 1-5.

[22] R. Cranfill and D. Moe (n.d.), "Deep Green-Hyperbolic Trees", http://ucjeps.berkeley.edu/htree_intro.html. 
[23] Letunic and P. Bork (2011), "Interactive Tree of Life v2: Online Annotation and Display of Phylogenetic Trees Made Easy”, Nucleic Acids Research 39: W475-W478.

[24] C. Matuk and D.H. Uttal (2012), "Narrative Spaces in the Representation and Understanding of Evolution", in K.S. Rosengren, S.K. Brem, E.M. Evans and G.M. Sinatra eds., Evolution Challenges: Integrating Research and Practice in Teaching and Learning About Evolution, Oxford University Press, Oxford, U.S.A., pp. 130-139.

[25] T. Ishikawa and T. Yamazaki (2009), "Showing Where to Go by Maps or Pictures: An Empirical Case Study at Subway Exits”, in K.S. Hornsby, C. Claramunt, M. Denis and G. Ligozat eds., Conference on Spatial Information Theory 2009. Lecture Notes in Computer Science, 5756: $330-241$.

[26] S.K. Card, J.D. Mackinlay and B. Shneiderman (1999), "Information Visualization", in S.K. Card, J.D. Mackinlay and B. Shneiderman eds., Readings in Information Visualization: Using Vision to Think, Morgan Kaufmann, San Francisco, U.S.A., pp. 1-34.

[27] J. Elkins (1999), The Domain of Images, Cornell University, Ithaca, U.S.A.

[28] M. Ruse (1991), “Are Pictures Really Necessary? The Case of Sewell Wright's 'Adaptive Landscapes", in proceedings of Biennial Meeting of the Philosophy of Science Association (1990), 3: $63-77$.

[29] S. Stephens (2012), "From Tree to Map: Using Cognitive Learning Theory to Suggest Alternative Ways to Visualize Macroevolution", Evolution: Education and Outreach 5: 603-618.

[30] J.H. Murray (1997), Hamlet on the Holodeck: The Future of Narrative in Cyberspace, Free Press, New York, U.S.A.

[31] S.J. Hackett et al. (2008), "A Phylogenomic Study of Birds Reveals Their Evolutionary History", Science 320: 1763-1768.

[32] J.W. Brown and M. van Tuinen (2011), "Evolving Perceptions on the Antiquity of the Modern Avian Tree", in G. Dyke and G. Kaiser eds., Living Dinosaurs: The Evolutionary History of Modern Birds, Wiley, Hoboken, U.S.A., pp. 3-8.

[33] K.F. Catley, L.R. Novick and C.K. Shade (2010), "Interpreting Evolutionary Diagrams: When Topology and Process Conflict”, J. Res. Sci. Teach. 47: 861-882.

[34] S.J. Gould (1995), "Ladders and Cones: Constraining Evolution by Canonical Icons", in R.B. Silvers ed., Hidden Histories of Science, New York Review, New York, U.S.A., pp. 33-67.

\section{Author}

Sonia H. Stephens is a postdoctoral researcher at the University of Central Florida, U.S.A. She received a MS in Botany and Ecology, Evolution, and Conservation Biology from the University of Hawaii U.S.A., and a PhD in Texts and Technology from the University of Central Florida. Her research interests include the use of metaphor, narrative, and interactive visualizations in science communication. Her current research focuses on developing interactive map-based narratives to communicate about sea level rise.

E-mail: sonia.stephens@ucf.edu.

How to CITE: S.H. Stephens, Communicating evolution with a Dynamic Evolutionary Map, JCOM 13(01)(2014)A04. 